\title{
English, Unish, and an Ideal International Language: From a Perspective of Speech Sound and Writing System
}

\author{
Young-Hee Jung \\ Sejong University
}

\begin{abstract}
In recent years, as international communication has become more frequent and significant, the obstacle that foreign language pose is more keenly felt and so the linguistic variety of the present world has become a heavy burden on international communication. In order to facilitate an international communication, various artificial languages have been constructed. In this paper, I examine Unish, one of the recently constructed artificial languages, and English, a dominant language of the present world, from the perspective of phonetics, phonology, and writing system. I argue that an ideal international language should not contain speech sounds that are not easy to produce, and its writing system should be phonemic. Unish, I show, contains consonant sounds that are not easy to produce. Writing system of Unish is in part not phonemic. English is found to contain too many vowel sounds, the aspect that makes acquisition of English difficult. Spelling system of English is the most problematic about English as an international language. An ideal international that is proposed contains the most frequent and easy-to-produce seventeen consonant sounds. It has a basic five-vowel system and its writing system is perfectly phonemic.
\end{abstract}


22 English, Unish, and an Ideal International Language: from a perspective of

Keywords: international communication, artificial language, Unish, phonetics, phonology, writing system, sound, phonemic, easy-toproduce consonant, five vowel system

\section{Introduction}

In his recently given speech, William Pfaff, a world affairs columnist, said that the United States has, since the end of World War II, been by far the greatest external influence on both Asia and Western Europe. Its cultural influence has been very wide; its economic influence has been far more important, imposing a structure on international relations that persists to the present day. If that structure changes, then the situation and possibilities of the European and of Asian governments and societies change in basic ways. This structure, he argues, is changing. After September 11, 2001, the American leadership has been weakened greatly, leaving an absence of power.

Not a few people agree with him in that the power of the United States is declining in the international society. The retreat of the United States from the international society will inevitably threat the status of English as a global language because no one can deny that the power of America, economical, political and military, is mainly responsible for the present status of English as the world language. The fact that the recent emergence of China in the international scene, economically and politically, triggered a boom of Chinese learning in many countries including Korea clearly shows that power and language is closely connected with each other in the international society.

The decline of English in the international society as the global language will result in absence of the common international language, putting a great burden on all parties engaging in international communication. The situation is analogous to the 
situation in Europe in 17th century when Latin's role as an international language has been weakened so that there was no dominant language in the international society. The enormous burden of international communication led Europeans to develop artificial languages. Similarly, in the near future it is likely that we will have no dominant language for international communication. Therefore, there is a growing need for an effective artificial language for international communication.

An artificial language will have speech and writing. Whatever their historical relationship, the fact remains that modern society makes available to its members two very different systems of communication, speech and writing, each of which has developed to fulfil a particular set of communicative needs. For instance, the relative permanence of written language makes it ideally suited for such functions as recording facts and communicating ideas. The immediacy of speech makes it ideal for social functions.

In this paper, I will consider a sound system and a writing system of an ideal international language. From these perspectives I will examine English and Unish, an artificial language recently developed.

\section{Speech Sounds of an Ideal International Language}

One of the main reasons we are not willing to use a natural language for international communication is that a natural language is not easy to learn. A natural language has irregular and complex grammar; the semantic formation of words is not clear; spelling is not phonetic; and it has difficult sounds to produce. An ideal international language should have a regular and simple grammar, semantic formation of words based on clear principles, phonetic spelling and easy sounds. In this section, I will consider an ideal 
24 English, Unish, and an Ideal International Language: from a perspective of

sound system for an international language. Then I will examine English and of Unish and show that they employ some sounds that are not easy to pronounce. I propose an ideal sound system that consists of 18 consonants such as [p, b, t, d, k, g, f, v, s, z, m, n, y, w, $\mathrm{j}, \mathrm{l}, \mathrm{h}]$ and five vowels of [a, e, i, o, u].

\subsection{A Consonant System of an Ideal International Language}

\subsubsection{Most Frequent Consonants}

Sounds of an international language should be easy to pronounce above all things. I assume that the sounds that turn up most frequently in the languages of the world are the easiest to pronounce. In Crystal (1987), the findings of the most common consonant segments are presented based on an American survey known as UPSID (the University of California, Los Angeles Phonological Segment Inventory Database). The inventories of 317 languages were included, with one language being selected from each family grouping recognized. The 20 most frequent consonants extracted from the UPSID file are listed in (1).

(1) 20 Most Frequent Consonants

\begin{tabular}{|l|c|c|c|c|c|}
\hline & labial & alveolar & palatal & velar & gloattal \\
\hline stop & $\mathrm{p}, \mathrm{b}$ & $\mathrm{t}, \mathrm{d}$ & $\mathrm{t}$ & $\mathrm{k}, \mathrm{g}$ & $\mathrm{P}$ \\
\hline fricative & $\mathrm{f}$ & $\mathrm{s}$ & $\int$ & & \\
\hline nasal & $\mathrm{m}$ & $\mathrm{n}$ & $\mathrm{n}$ & $\mathrm{g}$ & \\
\hline approximant & $\mathrm{w}$ & $\mathrm{1}, \mathrm{r}$ & $\mathrm{j}$ & & $\mathrm{h}$ \\
\hline
\end{tabular}

No language has exactly the system in (1). Most languages have between 14 and 16 of these segments. No one segment is found in all languages. The UPSID survey shows the typical range of consonant segments to be between five and eleven stops, two and 
four nasals and four others. Consonants in (1) can be assumed to be the easiest sounds to produce. So, the inventory in (1) should be an ideal inventory of consonants for an international language from a typological point of view.

\subsubsection{Universal Dependency, Symmetry, and Language Acquisition}

The consonant system in (1), however, is not ideal from a phonological view point. The system in (1) violates the universal tendency to symmetry found in the phonological systems of natural languages. For instance, English has a symmetrical system as in (2) and Czech has one in (3). A system like that of Siriono, a Bolivian language, in (4), which has holes in the pattern, is less common (Katamba 1997).

(2) English

\begin{tabular}{|l|c|c|c|}
\hline & bilabial & alveolar & velar \\
\hline voiceless & $\mathrm{p}$ & $\mathrm{t}$ & $\mathrm{k}$ \\
\hline voiced & $\mathrm{b}$ & $\mathrm{d}$ & $\mathrm{g}$ \\
\hline
\end{tabular}

(3) Czech

\begin{tabular}{|l|c|c|c|c|}
\hline & bilabial & alveolar & palatal & velar \\
\hline voiceless & $\mathrm{p}$ & $\mathrm{t}$ & $\mathrm{c}$ & $\mathrm{k}$ \\
\hline voiced & $\mathrm{b}$ & $\mathrm{d}$ & $\mathrm{j}$ & $\mathrm{g}$ \\
\hline
\end{tabular}

(4) Siriono

\begin{tabular}{|l|c|c|c|c|}
\hline & bilabial & alveolar & palatalized & velar \\
\hline voiceless & $\mathrm{p}$ & $\mathrm{t}$ & $\mathrm{k}^{\mathrm{j}}$ & $\mathrm{k}$ \\
\hline voiced & $\mathrm{b}$ & & & \\
\hline
\end{tabular}

For a language to be phonologically symmetrical is a way of 
26 English, Unish, and an Ideal International Language: from a perspective of

optimizing the use of phonetic parameters; it is a way of getting a relatively small number of different bundles of phonetic properties to do the job of distinguishing word meanings. Therefore, a symmetrical system is easier to learn than an asymmetrical one.

The consonant system in (1) is asymmetrical in the sense that labial and alveolar voiceless stops have has corresponding voiced ones but a palatal voiceless stop does not have one. The system in (1) also is asymmetrical in that voiceless stop sounds have their corresponding voiced ones but voiceless fricatives do not have their corresponding voiced one. A system where every stop and fricative has a corresponding voiceless one as in (5) is symmetrical and thus easier to learn.

(5)

\begin{tabular}{|l|c|c|c|c|c|}
\hline & labial & alveolar & palatal & velar & gloattal \\
\hline stop & $\mathrm{p}, \mathrm{b}$ & $\mathrm{t}, \mathrm{d}$ & $\mathrm{t}, \mathrm{d}$ & $\mathrm{k}, \mathrm{g}$ & $\mathrm{P}$ \\
\hline fricative & $\mathrm{f}, \mathrm{v}$ & $\mathrm{s}, \mathrm{z}$ & $\int, \mathrm{3}$ & & \\
\hline nasal & $\mathrm{m}$ & $\mathrm{n}$ & $\mathrm{n}$ & $\mathrm{g}$ & \\
\hline approximant & $\mathrm{w}$ & $\mathrm{1}, \mathrm{r}$ & $\mathrm{j}$ & & $\mathrm{h}$ \\
\hline
\end{tabular}

The system (5) is symmetrical and thus easier to learn than the system (1).

Child language acquisition also provides information on what are the sounds that are relatively easy to pronounce under the assumption that children acquire sounds that are easy to pronounce earlier than those that are not. It is reported in Crystal (1987) that $[\mathrm{h}$, $\mathrm{d}, \mathrm{b}, \mathrm{m}, \mathrm{t}, \mathrm{g}, \mathrm{s}, \mathrm{w}, \mathrm{n}, \mathrm{k}, \mathrm{j}, \mathrm{p}$ ] are among frequent English consonants of children of about one year old; $\left[\theta, \mathrm{t} \int, \mathrm{d} 3,3\right]$ are the most infrequent English consonants: they are seldom uttered by the children. Infrequent sounds in a child's language can be assumed to be difficult-to-pronounce sounds. The consonant system in (1) includes [?], and it is better to be excluded from the set, along with 
[?], its corresponding voiceless one.

\subsection{3. $[\mathrm{r}]$}

The sound $[r]$, in fact, represents several different types of " $r$ " sound. In Ladefoged (1993), 10 different " $r$ " sounds are listed: voiced alveolar trill [r] in Spanish, voiced alveolar flap [(] in Spanish, voiced retroflex flap [r] in Hausa, voiced alveolar approximant $[\mathrm{I}]$ in British English, voiced retroflex approximant $[\mathrm{I}]$ in American English, voiced alveolar fricative trill in Czech [ř $]$, voiced uvular trill $[\mathrm{R}]$ in Provencal-French, voiced uvular fricative or approximant $[\mathrm{G}]$ in Parisian-French, voiced bilabial trill [B] in Kele, and voiced labiodental flap ${ }^{1}$ in Margi. A variety of " $r$ " sound means no common, unitary pronunciation for " $r$ " sound among speakers of different languages. In this respect, [r] is not an appropriate sound for an international language.

\subsection{4. [?], [t], and [d]}

The glottal stop sound [?], the palatal stop sounds [t] and [d] are not proper for an international language in the sense that they are not common among major languages of the world. Major languages are languages that has more than 50,000,000 speakers. There are around 20 major languages: Chinese, English, Spanish, Hindi, Arabic, Malay, Bengali, Russian, Portuguese, Japanese, German, French, Urdu, Italian, Korean, Tagalog, Thai, Persian, Turkish, and Vietnamese. Considering that the main users of an international language will be the speakers of 20 major languages, and these three sounds are not easy to pronounce, it is desirable not to include them in an international language.

[r], [?], [t] and [d] excluded, we are left with the consonant

\urcorner There is no prescribed symbol for the sound. 
28 English, Unish, and an Ideal International Language: from a perspective of

system in (6), which I propose as an ideal consonant system for an international language.

(6) Consonant System of an Ideal International Language

\begin{tabular}{|l|c|c|c|c|c|}
\hline & labial & alveolar & palatal & velar & gloattal \\
\hline stop & $\mathrm{p}, \mathrm{b}$ & $\mathrm{t}, \mathrm{d}$ & & $\mathrm{k}, \mathrm{g}$ & \\
\hline fricative & $\mathrm{f}, \mathrm{v}$ & $\mathrm{s}, \mathrm{z}$ & & & \\
\hline nasal & $\mathrm{m}$ & $\mathrm{n}$ & & $\mathrm{y}$ & \\
\hline approximant & $\mathrm{w}$ & $\mathrm{l}$ & $\mathrm{y}$ & & $\mathrm{h}$ \\
\hline
\end{tabular}

\subsubsection{Consonant System of English and Unish}

English has 24 consonants as in (7).

(7) English Consonant System

\begin{tabular}{|l|c|c|c|c|c|c|}
\hline & bilabial & dental & alveolar & palatal & velar & glottal \\
\hline stop & $\mathrm{p}, \mathrm{b}$ & & $\mathrm{t}, \mathrm{d}$ & & $\mathrm{k}, \mathrm{g}$ & \\
\hline fricative & $\mathrm{f}, \mathrm{v}$ & $\theta, \partial$ & $\mathrm{s}, \mathrm{z}$ & $\int, 3$ & & \\
\hline affricate & & & & $\mathrm{t} \int, \mathrm{d} 3$ & & \\
\hline nasal & $\mathrm{m}$ & & $\mathrm{n}$ & & $\mathrm{y}$ & \\
\hline approximant & $\mathrm{w}$ & & $\mathrm{l}, \mathrm{r}$ & $\mathrm{j}$ & & $\mathrm{h}$ \\
\hline
\end{tabular}

Dental sounds $[\theta$, đ] are not only uncommon among the languages of the world but also is not easy to pronounce. So they are not proper sounds for an international language. The sounds $[\mathrm{t} S$, d3,3] are among the infrequent sounds of one-year old children, which suggests that they are not easy sounds to produce. Therefore, I argue that they are not fit for an international language. The sound [r] is not appropriate for an international language because, as I have argued in the previous section, it has different pronunciations from language to language.

Unish, an artificial language, has the following consonant system. 
(8) Unish Consonant System

\begin{tabular}{|l|c|c|c|c|c|}
\hline & abial & alveolar & palatal & velar & glottal \\
\hline stop & $\mathrm{p}, \mathrm{b}$ & $\mathrm{t}, \mathrm{d}$ & & $\mathrm{k}, \mathrm{g}$ & \\
\hline fricative & $\mathrm{f}, \mathrm{v}$ & $\mathrm{s}, \mathrm{z}$ & $\mathrm{S}$ & & \\
\hline affricate & & & $\mathrm{t} \int, \mathrm{d} 3$ & & \\
\hline nasal & $\mathrm{m}$ & $\mathrm{n}$ & & $\mathrm{y}$ & \\
\hline approximant & $\mathrm{w}$ & $\mathrm{1}, \mathrm{r}$ & $\mathrm{j}$ & & $\mathrm{h}$ \\
\hline
\end{tabular}

Unish has 21 consonants. As shown in the chart in (7), in the consonant system of Unish there is a gap in the pattern: there is no voiced palatal fricative corresponding to a voiceless palatal fricative $\left[\int\right]$

Unish has two affricates, [t $\left.\int\right]$ and [d3], both of which are not easy sounds to produce: they are not among the frequent consonants listed in (1); they also are not among the consonants acquired earlier by children.

Unish has [r] sound, which is not fit for an international language because it has different pronunciations from language to language.

\subsection{Vowel System of an Ideal International Language}

As vowels are more difficult to describe accurately than consonants, they are more difficult to acquire. Accordingly, a language that has many vowel sounds cannot serve as an ideal international language.

The smallest vowel (monophthong) systems turn out to have three members (fewer than $6 \%$ according to UPSID). The largest number of vowel segments is $24(! \mathrm{Xu})$. Most languages have between 5 and 7 vowels.

Out of 2549 vowel segments in the UPSID data a high front vowel [i] has the most tokens (452), which is followed by a mid back rounded vowel [o] with 448 tokens. A mid front vowel [e] has 425 tokens, which is followed by a high back rounded vowel [u] (Crystal 1987). A low vowel [a] has the fifth most tokens of 392. A 
30 English, Unish, and an Ideal International Language: from a perspective of

mid central unrounded vowel [ə] has the sixth-most tokens of 100 .

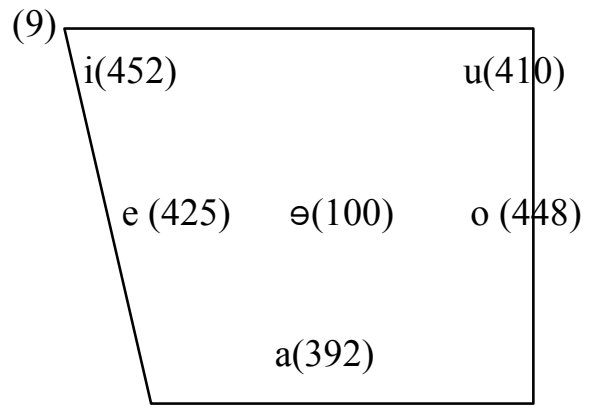

Note that there is a big difference in number of token between [a], the fifth vowel and [९], the sixth one. This suggests that the most frequent vowels of world languages are $[i, \mathrm{o}, \mathrm{e}, \mathrm{u}, \mathrm{a}]$. Thus, I propose the five vowel system of $[\mathrm{i}, \mathrm{o}, \mathrm{e}, \mathrm{u}, \mathrm{a}]$ for an international language.

\subsubsection{Vowel System of English and Unish}

English has a 12 vowel (monophthongs) system. Considering the number of vowels of most languages are between 5 and 7 vowels (Crystal, 1987), English has a relatively complicated one. As I argued earlier, the number of vowel sounds of a language adversely affects its learning: the more vowels a language contains, the more difficult learning the language is. Accordingly, the fact that English has many vowels makes its learning difficult.

Unish has a five-vowel system: $[i, \mathrm{o}, \mathrm{e}, \mathrm{u}, \mathrm{a}]$. They correspond to all and only the most frequent vowels of the world languages. Accordingly, the vowel system of Unish will be easily and readily acquired. 


\section{Writing System of an Ideal International Language}

There are three basic types of writing: logographic, syllabic and alphabetic. In the logographic system, each symbol represents a word. As a result, in the logographic system one must learn an enormous number of logographs before one can read and write. The best known case is Chinese.

In a syllabic writing system, each symbol represents a syllable, usually a consonant-vowel pair. Such systems have been found from earlier times and in modern times can be seen in Amharic, Cherokee, and Japanese kana. The number of graphemes in a syllabary variesfrom around 50 to several hundred.

The principle of alphabetic writing is that each letter represents a particular spoken sound of the language, which makes it the most economical and adaptable of all the writing systems. Instead of several thousand logograms, or several dozen syllables the system needs only a relatively small number of units, which then proves easy to adapt to a wide range of languages. Most alphabets contain 20-30 symbols.

The alphabetic writing system is ideal for an international language. There are many different alphabetic scripts used in the world. The roman alphabet is one of them. As English has the most speakers (native speakers and ESL speakers included) next to Chinese, the roman alphabet, which is the writing system of English, will be the most wide-spread and familiar writing system, so will be the best candidate for an international language.

The roman alphabet needs to be modified by eliminating some letters and adding new symbols in order to be used for an international language proposed in this paper. Under the principle that a one-to-one correspondence is established between letters and sounds, the 17 consonant sounds [p, b, t, d, k, g, f, v, s, z, m, n, y, l, y, $\mathrm{w}, \mathrm{h}$ ] proposed above for an ideal international language are directly 
32 English, Unish, and an Ideal International Language: from a perspective of

represented by the roman alphabets except the velar nasal [ $\mathrm{y}]$. As a result, the roman alphabet letters such as $r, c, j, x$, and $q$ are not in use. For the velar nasal we need to add a new symbol because there is no letter in the roman alphabet that represents the sound. I propose a symbol [y] for a velar nasal. The symbol combines a velar voiced stop sound $[\mathrm{g}]$ and an alveolar nasal sound [n].

For the vowel sounds, we can use five roman alphabet letters $a, e$ $i, o, u$. as they are. So, the alphabet system for an ideal international language looks like the following:

(10) a. Letters for Consonants

$\mathrm{p}, \mathrm{b}, \mathrm{t}, \mathrm{d}, \mathrm{k}, \mathrm{g}, \mathrm{f}, \mathrm{v}, \mathrm{s}, \mathrm{z}, \mathrm{m}, \mathrm{n}, \mathrm{y}, \mathrm{l}, \mathrm{w}, \mathrm{y}, \mathrm{h}$

b. Letters for Vowels

$\mathrm{a}, \mathrm{e}, \mathrm{i}, \mathrm{o}, \mathrm{u}$

\subsection{English Writing System}

The English writing system is basically phonemic: each letter represents a particular spoken sound of the language. However, only a few letters of the English alphabet are usually related to one and only one sound: in many cases a one-to-one correspondence between letters and sounds is violated. Modern English spelling is about four hundred years old, and English pronunciation has changed a good deal in that time, which is why its spelling seems peculiar at times.

The one-to-one correspondence between sounds and letters is more violated in vowels than in consonants of English. The mismatch between vowel sounds and vowel letters is unavoidable in English because English has 15 vowel sounds but the English alphabet has only five letters [a, e, i, o, u] to represent vowels. In the case of consonants, the number of sounds and letters to represent them approximates: there are 24 consonant sounds of English and 22 letters to represent them. 
Though historically writing system may derive from speech, in modern society the dependence is mutual. Considering an important role of writing in modern society, it is clear that English, which is notorious for exceptions in a one-to-one correspondence between letters and sounds, cannot be the best choice as the international language for modern society.

\subsection{Unish Writing System}

Unish has 25 letters for consonant sounds and five letters for vowel sounds. In (11) the letters and the sounds they represent are shown.

(11) a. Consonants

$\begin{array}{cccc}\text { Letters } & \text { Sounds } & \text { Letters } & \begin{array}{c}\text { Sounds } \\ \mathrm{b}\end{array} \\ \mathrm{d}] & \mathrm{p} & {[\mathrm{p}]} \\ \mathrm{d} & {[\mathrm{d}]} & \mathrm{q} & {[\mathrm{kw}]} \\ \mathrm{f} & {[\mathrm{f}]} & \mathrm{r} & {[\mathrm{r}]} \\ \mathrm{g} & {[\mathrm{g}]} & \mathrm{s} & {[\mathrm{s}]} \\ \mathrm{h} & {[\mathrm{h}]} & \mathrm{t} & {[\mathrm{t}]} \\ \mathrm{j} & {[\mathrm{P}]} & \mathrm{v} & {[\mathrm{v}]} \\ \mathrm{k} & {[\mathrm{k}]} & \mathrm{x} & {[\mathrm{ks}]} \\ \mathrm{l} & {[\mathrm{l}]} & \mathrm{z} & {[\mathrm{z}]} \\ \mathrm{m} & {[\mathrm{m}]} & \mathrm{ch} & {[?]} \\ \mathrm{n} & {[\mathrm{n}]} & \mathrm{ng} & {[\mathrm{y}]} \\ \mathrm{y} & {[\mathrm{y}]} & \mathrm{sh} & {[?]} \\ \mathrm{w} & {[\mathrm{w}]} & & \\ \text { b. Vowels } & & & \\ \mathrm{i} & {[\mathrm{i}]} & \mathrm{e} & {[\mathrm{e}]} \\ \mathrm{a} & {[\mathrm{a}]} & \mathrm{o} & {[\mathrm{o}]} \\ \mathrm{u} & {[\mathrm{u}]} & & \end{array}$

The writing system of Unish is basically phonemic. However, a 
34 English, Unish, and an Ideal International Language: from a perspective of

one-to-one correspondence between sounds and letters is violated in some cases where a sound is represented by a diagraph (two letters) and a sequence of two sounds are represented by a letter. For instance, the letter $q$ of Unish represents the sound sequence [kw] and the letter $x$ represents the sound sequence [ks]. So in Unish [teksi] 'taxi' is spelled as texi where $\mathrm{x}$ represents [ks], and [kwit] 'quit' is spelled as qit where $q$ represents [kw]. Unish just adopts an English orthographic tradition in which [kw] and [ks] are represented by the letter $q$ and $x$ respectively.

However, there is no logical or phonetic/phonological reason why the sequence of sounds [kw] and [ks] should be represented by a single letter. As $[\mathrm{kw}]$ or [ks] is not a single sound, it should not be represented by a single letter according to the phonemic principle. Moreover, as Unish has an independent letter $k$ for the sound [k], a letter $w$ for the sound [w] and a letter $s$ for [s], there is no need for assigning independent letters to the sound sequences of $[\mathrm{kw}]$ and [ks]: [kw] can simply be represented by $-k w$ - and [ks], by $-k s^{-}$.

A reverse case is also found in Unish: a single sound [S] is represented by a diagraph (two letters) [sh], [y] is represented by [ng], and [t $\left.\int\right]$ by [ch]. Using a diagraph to represent a single sound is not desirable not just because it violates a phonemic principle of one-letter/one sound. It is not also desirable because since each letter of a diagraph, used separately, represents a sound by itself, it will not be clear whether a diagraph represents a third, independent sound or a sequence of the sounds each letter of a diagraph separately represents. For instance, a word like tongin will be pronounced in Unish either as [tonin] if we take $n g$ as a diagraph or as [tongin] if we take $n g$ simply as a sequence of $n$ and $g$.

In conclusion, though Unish writing system has been intended to be phonemic, it violates in part one letter/one sound principle. 


\subsection{Sound Change}

Language is constantly changing, whereas writing systems tend to be preserved. Unish will not be an exception to this fact. This means that no matter how perfectly we construct a writing system according to the principle of one letter/one sound principle, the inconsistency between letters and sounds will be inevitable as time goes. Therefore, in order to maintain consistency between spelling and pronunciation, spelling reforms will be needed to catch up with the pronunciation changes.

\section{Conclusion}

The phonetic/phonology system and writing system of English and Unish have been examined. It has been shown that English contains consonant sounds that are difficult to produce. Vowels are more problematic. English contains many vowel sounds (12 monophthongs and 3 diphthongs). Considering that 5 to 7 is the average number of vowel sounds of the world languages, and that vowels are more difficult to acquire than consonants, a large number of vowels will be a disadvantage of English as an international language. However, the most problematic aspect of English as an international language is spelling. In so many cases, the phonemic principle of a one-to-one correspondence between letters and sounds is violated. Unish contains some consonants that are difficult to produce. The writing system of Unish in part violates the phonemic principle: a combination of two independently used letters represents a single sound and reversely a sequence of two sounds is represented by a single letter.

A sound system of an ideal international language has been proposed. It contains 17 most frequent and easy-to-produce consonant sounds and 5 basic vowels. Its spelling system is 
36 English, Unish, and an Ideal International Language: from a perspective of

perfectly phonemic, so that a one-to-one correspondence between letters and sounds is established.

\section{References}

Crystal, D. 1987. The Cambridge Encyclopedia of Language. Cambridge: Cambridge University Press.

Chung, Y.-H. 1995. An International Language for the World to Come. Journal of Universal Language 1, 56-70.

. 1996. A Prospect for an International Language in 2045. A Vision 2045, 469-478. Seoul: Sejong Publisher Co.

Dewey, G. 1971. English Spelling: Roadblock to Reading. New York: Columbia University Press.

Fishman, J., R. Cooper, \& A. Conrad. 1977. The Spread of English. Rowley, MA: Newbury House Publisher, Inc.

Gimson, A. 1980. An Introduction to the Pronunciation of English. London: Edward Arnold.

Katamba, F. 1989. An Introduction to Phonology. London \& New York: Longman.

1994. English Words. London: Routledge.

Ladefoged, P. 1982. A Course in Phonetics. New York: Harcourt Brace Jovanovich.

Large, A. 1983. The Artificial Language Movement. Oxford: Basil Blackwell.

Phillipson, R. 1992. Linguistic Imperialism. Cambridge: Oxford University Press. 